\section{LES COL·LECCIONS BIBLIOGRÀFIQUES D'ALEXANDRE DE RIQUER A LA BIBLIOTECA JOAQUIM FOLCH I TORRES DEL MUSEU NACIONAL D'ART DE CATALUNYA}

\section{Introducció}

Durant el 2020 es compleixen cent anys de la mort de l'artista Alexandre de Riquer (1856-1920), home polifacètic i un dels principals representants del Modernisme a Catalunya. Conreà disciplines diverses com la pintura, la decoració, el dibuix, el gravat, el cartellisme o la il·lustració de llibres, a més del seu vessant col·leccionista.

La figura artística d'Alexandre de Riquer ha estat brillantment estudiada per experts com Eliseu Trenc, Pilar Vélez o Joan-Lluís Yebra. Malgrat que Alexandre de Riquer sentia passió pel col·leccionisme, la seva faceta col-leccionadora és més desconeguda. Des de molt jove, l'artista es va dedicar a cercar per encants i antiquaris amb la finalitat d'adquirir peces. Aquesta inclinació el va unir a Santiago Rusiñol i Miquel Utrillo amb els qui viatjà pel Pirineu I'any 1887 a la recerca d'antiguitats. Tots tres eren aficionats a la pintura antiga i a l'art decoratiu, assidus d'antiquaris i buscadors de peces valuoses. ${ }^{1}$

El taller d'Alexandre de Riquer, situat al carrer de la Freneria, es convertí en un petit museu que mostrava generosament a qui estava interessat. Pel Iloc passaren artistes i intel·lectuals, molts d'ells també col·leccionistes, que pertanyien a un cercle d'erudits. Les col-leccions d'Alexandre de Riquer eren eclèctiques. Bartomeu Sigalés ${ }^{2}$ explica com les parets de I'estudi de l'artista estaven plenes de pintures, d'objectes de ceràmica, de miniatures, d'estatuetes i de marcs; o com els armaris estaven atapeïts de llibres d'art, manuscrits, incunables i volums enquadernats per ell. De la mateixa manera, el testimoni de Joaquim Renart ${ }^{3}$ dóna notícia de les seves riques col-leccions de llibres, de papers de guardes, de dibuixos dels segles XVII i XVIII, d'esplèndids marcs i d'exlibris antics.

També Eliseu Trenc ${ }^{4}$ parla de la faceta col·leccionista de I'artista català fent un repàs per diverses col·leccions que va aplegar al Ilarg de la seva
MATÈRIA, núm. 18-19, 2021 ISSN 1579-2641, p. 117-137

Recepció: 13-09-2020

Acceptació: 13-1-2021

${ }^{1}$ Pla, Josep. Santiago Rusiñol $i$ el seu temps. Barcelona, Destino, 1981, p. 41.

Trenc Ballester, Eliseu. Alexandre de Riquer. Barcelona, Lunwerg, 2000, p. 30.

Cal remarcar que molts artistes espanyols i catalans van participar activament en el mercat artístic entre els anys deu i vint del segle passat, sovint motivats per una curiositat intel-lectual de coneixement dels mestres antics i moltes vegades per I'afany de col-leccionar. DOMÈNECH, Ignasi, "Miquel Utrillo, mercat de l'art i el col·leccionisme», Bonaventura BASSEGODA i Ignasi Domènech (eds.), Mercat de I'art, col-leccionisme i museus: estudis sobre el patrimoni artístic a Catalunya als segles XIX i XX, Bellaterra, Universitat Autònoma de Barcelona, 2014, p. 121-122.

2 Sigalés, Bartomeu, "N'Alexandre de Riquer». Vell i Nou, juny, 1921, p. 85-90. 
3 Renart, Joaquim, Diari 1918-1961. Barcelona, Destino, 1975, p. 77 i 78.

4 Trenc, Eliseu, "Alexandre de Riquer», Repertori de colleccionistes i col/leccions d'art i Arqueologia de Catalunya, [en línia] http://coleccions.recerca. iec.cat/2019/06/18/colleccions/ (consultat 12/1/2021)

TREnc, Eliseu. "Alexandre de Riquer, bibliòfil, "connoiseur" i col·leccionista», Bonaventura BASSEGODA i Ignasi Domènech (eds.), Agents del mercat artístic i col-leccionistes: nous estudis sobre el patrimoni artístic de Catalunya als segles XIX i XX, Bellaterra, Universitat Autònoma de Barcelona, 2017, p. 157-179.

5 «[...] Riquer també va deixar la seva empremta al Cau Ferrat de Santiago Rusiñol per la seva faceta de colleccionista de vidre. Propietari d'un inventari format per peces de I'antiguitat clàssica, medievals i dels segles XVI al $X V I I I$, que va ser adquirit per Rusiñol I'any 1902 i que van ser l'origen de la col·lecció de vidre antic del Cau Ferrat».

Garcia, Xavier, "Els museus de Sitges se sumen a la commemoració de I'Any Alexandre de Riquer», [en línia] https://museusdesitges.wordpress. com/2020/11/09/els-museusde-sitges-se-sumen-a-la-commemoracio-de-lany-alexandre-de-riquer/ (consultat el 12/1/2021)

6 Expedient ANC-715-T2386: "Llegat testamentari d'Emili Cabot i Rovira consistent en una col-lecció de vidres artístics i d'un tríptic flamenc del segle XV per a ser destinat a la Sala Cabot del Museu d'Art i d'Arqueologia».

7 Utrillo, Miquel. Història anecòtica del Cau Ferrat, vida i ressaltant com Riquer formava part d'un grup d'artistes que exercien $d^{\prime}$ 'antiquaris amb categoria de connoisseurs, d'experts.

Actualment, algunes de les col·leccions que van pertànyer a Alexandre de Riquer es conserven en institucions públiques. La col·lecció de vidres es troba repartida entre el Museu Cau Ferrat de Sitges ${ }^{5}$-va ser adquirida per Rusiñol I'any 1902- i el Museu del Disseny de Barcelona, ${ }^{6}$ on va ingressar per disposició testamentària d'Emili Cabot I'any 1924 quan encara era el Museu d'Art i Arqueologia. Sobre I'adquisició per part de Santiago Rusiñol i Emili Cabot de la col·lecció de vidres d'Alexandre de Riquer, circulen dues versions: Miquel Utrillo afirma que Santiago Rusiñol es va trobar amb Alexandre de Riquer en una vetllada al Cafè Continental on van pactar un preu de vuit mil pessetes per la venda. ${ }^{7}$ En canvi, Josep Maria de Riquer i Palau explica que el seu pare va regalar seva col·lecció a Santiago Rusiñol, Miquel Utrillo i Emili Cabot. ${ }^{8}$ Les dues versions no són del tot contradictòries i existeix la possibilitat que, després d'un gest impulsiu per part d'Alexandre de Riquer, Rusiñol el compensés econòmicament atès que existeix un rebut que en demostra la venda. ${ }^{9}$

La col·lecció de miniatures es troba al Museu del Disseny de Barcelona ${ }^{10}$ i la de dibuixos, al Gabinet de Dibuixos i Gravats del Museu Nacional d'Art de Catalunya. Aquest Gabinet també custodia el corpus de cartells impresos, principalment d'artistes nord-americans, que va reunir I'artista.

A més, Riquer tenia una faceta bibliòfila que el dugué a reunir diferents sèries relacionades amb el llibre: un recull de gravats i un altre d'exlibris que es conserven igualment al Gabinet de Dibuixos i Gravats. De la mateixa manera, la seva passió pel llibre el va fer aplegar un conjunt de relligadures antigues i un altre de papers de guardes decorats. Gràcies a la seva bibliofília, la Biblioteca Joaquim Folch i Torres del Museu Nacional d'Art de Catalunya atresora un interessant fons bibliogràfic patrimonial.

L'article pretén profunditzar en el coneixement dels fons, que eren propietat d'Alexandre de Riquer i que actualment es conserven en aquest centre. Parlem de la seva col·lecció d'enquadernacions artístiques, de I'exemplar incunable del Breviarium cartusianum i de part de la seva biblioteca privada. Tots aquests fons van ser adquirits per la Junta de Museus en anys diferents: la col·lecció de relligadures va ser adquirida I'any 1909 i I'exemplar incunable el 1914, però no van passar a formar part del fons de la Biblioteca dels Museus d'Art fins a I'any 1948. ${ }^{11} \mathrm{La}$ seva llibreria privada va ser comprada I'any 1921 i aquest mateix any va ingressar en la biblioteca. 


\section{La col·lecció d'enquadernacions artístiques adquirida I'any 1909}

Alexandre de Riquer va aplegar la seva col·lecció d'enquadernacions artístiques $^{12}$ en un moment en el qual el col-leccionisme de llibres era un fenomen habitual i en el que hi havia casos remarcables arreu el món. Als Estats Units, John Pierpont Morgan (1837-1913) havia reunit una magnífica col-lecció de manuscrits, llibres rars i incunables. A Espanya destacaven les dels bibliòfils Manuel Rico y Sinobas (1819-1898), Francisco de Zabalburu (1826-1897), José Lameyer González (1862-1877), José Lázaro Galdiano (1862-1947) i Bartolomé March Servera (1917-1998). A Catalunya, podem parlar de les d'Isidre Bonsoms (1849-1922), Pau Font de Rubinat (1860-1948) i Víctor Balaguer (1824-1901).

L'artista era membre fundador de I'Associació Catalana de Bibliòfils i es freqüentava amb amants del Ilibre d'arreu d'Europa com, per exemple, Octave Uzanne, reconegut bibliòfil francès, amb qui va visitar el Museu d'Art i Aqueologia de Barcelona. ${ }^{13}$ D'altra banda, també va mostrar gran interès pel coneixement històric de les relligadures $i$, per aquest motiu, tenia diverses obres sobre enquadernació i bibliofília a la seva biblioteca privada: La reliure moderne artistique et fantaisiste, $\mathrm{d}^{\prime}$ Octave Uzanne, ${ }^{14} \mathrm{O} \mathrm{La}$ reliure moderne artistique et fantaisiste, d'Émile Bosquet, ${ }^{15}$ com també un

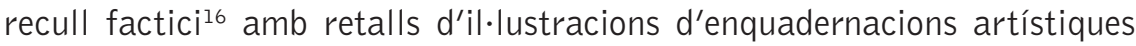
extrets de diversos llibres i revistes.

Riquer, que era plenament conscient del valor econòmic de les seves col·leccions, ${ }^{17}$ va proposar la venda de diverses peces a la Junta de Museus el mes de novembre de I'any 1909. L'oferta era de vint-i-tres miniatures i tres dibuixos, un conjunt de llibres il.lustrats del segle xviII, setanta enquadernacions antigues, cent quaranta-cinc dibuixos de mestres antics, un grup de Ilibres incunables, una crònica del segle xiv del Monestir de San Salvador de Oña, un àlbum amb tres-cents papers de guarda i setze pintures a I'oli. ${ }^{18}$

Inicialment, la Junta de Museus només va considerar oportú comprar la col·lecció de relligadures artístiques, refusant la resta d'oferiments, però finalment el 24 de desembre de 1909 va aprovar la compra conjunta de la col·lecció d'enquadernacions artístiques i de la de miniatures per un import de sis mil cinc-centes pessetes. ${ }^{19}$

En aquest article deixarem de banda el conjunt de miniatures atès que no es conserva en la Biblioteca Joaquim Folch i Torres, ${ }^{20}$ per centrar-nos exclusivament en la d'enquadernacions artístiques. Aquesta col·lecció està formada per vuitanta-cinc enquadernacions - de les quals vint-i-nou són exemptes- ${ }^{21}$ però no va ingressar en la biblioteca fins a l'any 1948 perquè,
Sitges, Grup d'Estudis Sitgetans, 1989, p. 53.

8 Riquer Palau, Josep Maria. "Quan el meu pare ja no era noi: biopsicologia d'Alexandre de Riquer», Alexandre de Riquer: I'home, I'artista, el poeta: modernisme simbolista, Calaf, Comissió organitzadora de I'homenatge a Alexandre de Riquer, 1978, p. 32.

9 Laplana, Josep de C., Santiago Rusiñol: el pintor, I'home, Barcelona, Publicacions de I'Abadia de Montserrat, 1995, p. 26.

10 «Respecte a la col·lecció de miniatures que la Junta va adquirir el 24 de desembre de 1909 i que actualmente és al Museu del Disseny de Barcelona, segons una relació que Josep Capsir m'ha comunicat molt amablement, la donació de Riquer degué ser de vint-i-vuit miniatures. [...] La col·lecció Riquer es componia essencialment de miniatures anònimes del segle XIX, dels anys 1830, de retrats sobre ivori.»

TREnc, Eliseu, op. cit., p. 171.

11 La Biblioteca Joaquim Folch i Torres ha tingut diverses denominacions al llarg de la seva historia. En aquests anys, es coneixia amb el nom de Biblioteca de los Museos de Arte, com podem comprovar en un directori de I'any 1951. Viña, Alberto, Las bibliotecas de Barcelona, Barcelona, Gremios de Editores y Libreros, 1951.

12 Camarero Roca, María Luisa; RuIz RuIz, Yolanda. "La colección de encuadernaciones de la Biblioteca del Museu Nacional d'Art de Catalunya (MNAC): catálogo de las tapas de encuadernación de la colección Riquer». Encuadernación de Arte [Madrid: AFEDA], núm. 39 , 2011, p. 21-57. 
13 En una carta d'Alexandre de Riquer que es conserva a I'Arxiu Nacional de Catalunya (d'ara en endavant, ANC) I'artista afirma: «En cuant a les encuadernacions, visitant el Museo ab el célebre critic d'art Octave Uzanne [autor de La relieure moderne, París, Édouard Rouveyre], persona a qui jo acompanyava, va preguntarme si sens indiscreció, podia demanarme lo que el Museo mi havia abonat per la colecció d'encuadernacions».

Expedient ANC1-715-T-2124: «Sessió del 24 d'octubre de 1914 de la Junta de Museus de Barcelona». Imatge 19/64.

14 Uzanne, Octave, La reliure moderne artistique et fantaisiste, Paris, É. Rouveyre, 1887.

${ }^{15}$ Bosquet, Émile, La reliure: études d'un praticien sur I'histoire et la technologie de l'art du relieur-doreur, Paris, Imprimerie Générale Lahure, 1894.

16 [Recull factici de 107 retalls d'il.lustracions d'enquadernacions], [S.I., S.n., ca.1900].

Procedeix d'una carpeta antiga amb el títol Recull format per l'artista $A$. de Riquer de 91 retalls de revistes il/lustrades, contenint facsímils de tapes ornades de relligatge. També conté en tres fulles soltes dissenys d'idèntic tema, obra de dit artista. En el contingut podem trobar, entre d'altres: 40 retalls d'enquadernacions de Charles Meunier procedents de la revista Reliure d'art, cinc retalls d'enquadernacions $d^{\prime}$ Albert Angus Turbayne i tres calcs a llapis de relligadures antigues.

17 A la carta d'Alexandre de Riquer citada anteriorment afirma: «en aquell temps jo rebia tots els catàlecs ab preus en el moment de la seva adquisició, es va considerar que resultava de gran utilitat per a l'estudi de les arts decoratives 22 i va passar a formar part del fons del Museu d'Art Decoratiu i Arqueològic, situat a I'antic Arsenal de la Ciutadella.

L'any 1932, amb la inauguració del Museu de les Arts Decoratives al Palau Reial de Pedralbes, les enquadernacions van ser traslladades a aquesta institució i instal-lades a la Sala v, també anomenada d'Eduard Toda. En aquesta ubicació van romandre fins que I'any 1936, amb I'esclat de la Guerra Civil espanyola, els fons dels museus barcelonins van ser trasIladats a Olot per procurar la seva protecció i salvaguarda durant la contesa bèl-lica.

Finalitzada la guerra, el Palau Reial de Pedralbes es va condicionar per a I'ús privat del nou Cap d'Estat. Per aquest motiu, fou necessària la cerca d'un nou emplaçament on ubicar les col·leccions. El lloc triat va ser el Palau de la Virreina, adquirit el 1944 i remodelat amb aquesta finalitat. La inauguració del nou museu d'arts decoratives es va produir I'any 1949. Els nous espais expositius eren semblants als anteriors, però les enquadernacions artístiques van desaparèixer del discurs dispositiu atès que s'havien ingressat i registrat en la Biblioteca dels Museus d'Art I'any 1948.

\section{Composició de la col·lecció}

La col·lecció d'enquadernacions artístiques, ${ }^{23}$ tot i no ser nombrosa i de no comptar amb exemples de tots els estils, períodes i països, té un valor innegable pel fet $d$ 'haver estat reunida per Alexandre de Riquer, un dels artistes cabdals del Modernisme que, a més, va mantenir una estreta relació amb el món del llibre, tant des del punt de vista artístic com del bibliòfil.

Els exemplars que la comprenen són majoritàriament d'origen espanyol dels segles Xv a XIx. S'hi apleguen relligadures gòtiques, mudèjars, renaixentistes, barroques, neoclàssiques, d'estil imperi i romàntiques que permeten observar, a grans trets, I'evolució de l'art de l'enquadernació i alguns dels seus principals estils.

El conjunt es troba catalogat i introduït en la seva totalitat a la Memòria Digital de Catalunya (MDC). ${ }^{24}$ Per això no farem una relació detallada, sinó que només ens detindrem en algunes peces singulars.

La primera peça destacable és un volum d'estil gòtic, ${ }^{25}$ el gust predominant a I'Europa Occidental entre el segle XIII i el començament del xv. La base de les tapes de les enquadernacions gòtiques era de fusta (roure, alzina, faig, olivera i, més escassament, de cedre), recobertes de pell (porc, vedell o cabra i pergamí, sempre en el seu color natural) i amb tancaments 
de fermalls metàl-lics. L'estructura decorativa es desenvolupava a partir de gofrats, amb bandes horitzontals, verticals i obliqües que configuraven rombes, triangles i rectangles.

Trobem també diversos exemplars mudèjars. L'estil mudèjar es va originar a la Península Ibèrica i, des d'aquí, es va difondre per tota l'Europa mediterrània. Aquest estil va trobar un excel·lent camp de creació en l'art de I'enquadernació en què els artesans van desplegar un gran repertori de geometries i llaceries. A Itàlia, aquestes enquadernacions foren confeccionades per enquadernadors peninsulars que havien arribat a la cort napolitana durant el regnat d'Alfons el Magnànim.

Avançada la segona meitat del segle xv, sorgí a Itàlia l'estil renaixentista encoratjat per I'humanisme i la progressiva expansió de la impremta. La necessitat d'abaratir costos va portar a inventar la roda, un petit cilindre metàl-lic amb un motiu gravat en la superfície que permet la seva repe-

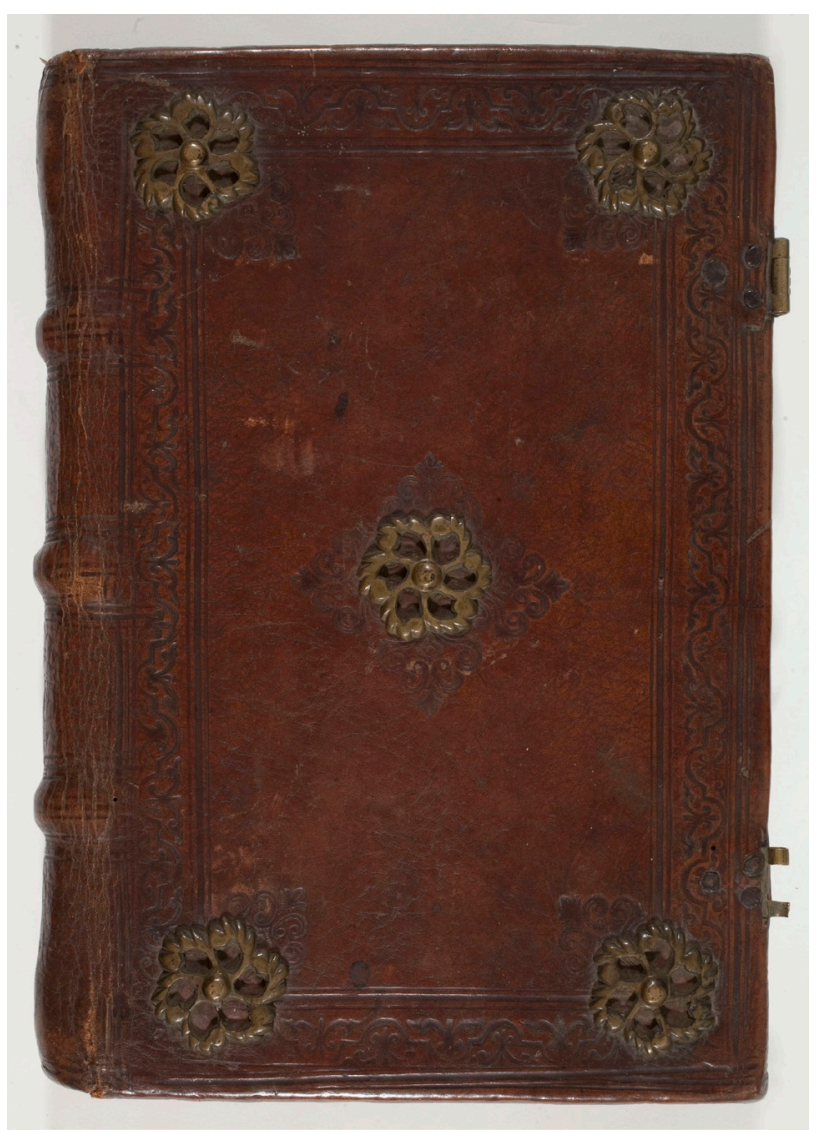

Fig. 1. Enquadernació d'estil gòtic al marge i seguia ab interes totes les ventes».

Expedient ANC1-715-T-2124: «Sessió del 24 d’octubre de 1914 de la Junta de Museus de Barcelona». Imatge 19/64.

${ }^{18}$ La relació detallada de les peces i els preus que demanava consta en una carta $d^{\prime}$ Alexandre de Riquer que es conserva a I'ANC.

Expedient ANC1-715-T-1978. «Sessió del 24 de desembre de 1909 de la Junta de Museus de Barcelona». Imatges 8-9/53.

19 Expedient ANCl715-T-414 «Acta de la sessió de la Junta de Museus de Barcelona de 24.12.1909 (inclou diligència d'ajornament de la convocatòria del dia 23.12.1909)». Imatge 3/8.

L'arxiu del Museu Nacional d'Art de Catalunya conserva un inventari on es relacionen les vuitanta-cinc enquadernacions comprades el 1909, a les que se li assignà un número $d$ 'inventari dels Museus $\mathrm{d}^{\prime}$ Art de Barcelona (MAB).

${ }^{20}$ Com ja hem mencionat anteriorment, aquesta col.lecció es trova dipositada al Museu del Disseny de Barcelona.

21 Una enquadernació exempta és una enquadernació dissociada del llibre o volum del qual formava part originàriament.

${ }^{22}$ «La interesante, numerosa y variada colección de encuadernaciones, adquirida de D. Alejandro de Riquer, juntamente con la de miniaturas, prestarán nuevo aliciente al conjunto general del Museo y serán de indudable provecho para el estudio y progreso de estas ramas importantísimas del Arte Industrial y las Artes Puras». Arxiu del Museu Nacional d'Art de Catalunya, Fons Biblioteca dels Museus d'Art, Enquadernacions, R.829. 
23 Un inventari realitzat a la dècada de 1970 va detectar que faltava un volum complet i tres enquadernacions exemptes.

24 «Enquadernacions artístiques de la Biblioteca Joaquim Folch i Torres ( MNAC)», Memòria Digital de Catalunya, [en línia], http://mdc. csuc.cat/cdm/landingpage/ collection/Enquade M N AC (consultat el 4/08/2020).

25 Aquest volum es tracta d'un reemboitage, I'enquadernació d'un volum més modern que reaprofita I'enquadernació antiga d’un altre llibre.

26 Checa Cremades, José Luis, Los estilos de encuadernación: siglos III d. J.C.- siglo XIX, Madrid, Ollero y Ramos, 2003, p. 243. tició, que va produir canvis en I'aspecte decoratiu, reflectit principalment en I'aparició d'orles concèntriques. També, la cerca de nous mercats entre els nobles, els rics mercaders i I'alta burocràcia provocà també canvis en les tècniques decoratives com l'ús de daurats. Com afirma Checa Cremades, la utilització de l'or té una doble lectura: és, per una part, una metàfora visual dels nous temps, de l'emergent cultura humanista i, per altra, és una manifestació directa de riquesa i la fortuna dels posseïdors. ${ }^{26}$

Destaca especialment una enquadernació italiana de plaquetes. Aquest tipus representava un grup ornamental molt característic entre les enquadernacions renaixentistes $i$ el seu tret principal és la utilització d'un ornament amb forma circular, semblant a una medalla, en el centre de la tapa.

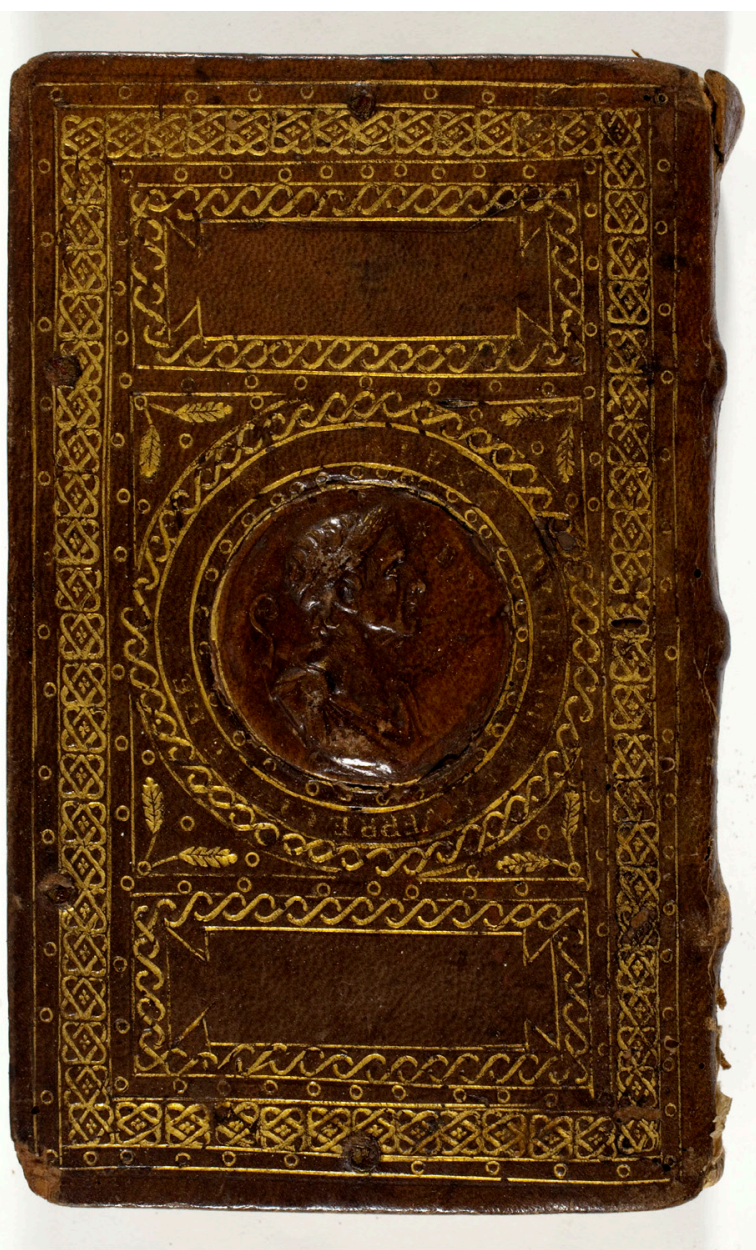

Fig. 2. Enquadernació renaixentista de plaquetes 
La col·lecció compta amb dos exemplars d'estil plateresc, exclusiu del Renaixement espanyol, que es caracteritza per tenir una estructura decorativa a base de requadres (també poden ser octògons, rombes, etc.) i un espai central decorat amb ferros solts gofrats o daurats amb motius diversos: animals, medallons, ferros aldins, etc.

També hi ha un exemple d'enquadernació dels anomenats «tipus populars». Aquest estil va aparèixer a Espanya a cavall entre els segles XVI i xVII, constituint I'estil de transició entre el plateresc i el barroc i es distingeix per utilitzar figures geomètriques, com ara rombes, hexàgons i quadrats. En la seva decoració s'aprecia la influència d'arts populars com les puntes, la passamaneria i les reixades. És molt distintiva la utilització d'una sèrie de ferros amb forma de balustres, arquets, llengües de foc o flames ondulants. La denominació de "tipus populars» va ser divulgada per Matilde López Serrano ${ }^{27}$ i sol ser pròpia de les vistoses cartes d'executòria de noblesa realitzades al voltant de les cancelleries de Saragossa, Granada i Valladolid. ${ }^{28}$

Les enquadernacions barroques se singularitzen per l'excés ornamental, una acurada execució i una gran riquesa iconogràfica. Dins d'aquest estil, els especialistes reconeixen diversos grups, alguns dels quals són presents a la col·lecció d'Alexandre de Riquer i que, a continuació, ressenyem.

En primer $\|$ oc, hi ha l'estil à la fanfare (o enquadernacions de ramejats) del qual trobem un parell d'enquadernacions. Es caracteritzen per tenir la superfície de les tapes dividida en espais geomètrics i un espai central envoltat de decoració daurada amb ramejats de flors, palmes o branques de Ilorer. La decoració està realitzada mitjançant ferros diminuts que exigeixen un domini absolut de la tècnica del daurat.

També tenim les denominades enquadernacions de ventalls, aparegudes a Espanya durant el primer terç del segle xvir. A la col·lecció d'Alexandre de Riquer trobem dos exemples d'aquest tipus d'enquadernació que té com característica principal la decoració de les tapes amb figures semblants a les varetes desplegades d'un ventall que s'aconsegueix per la repetició radial d'un mateix ferro.

D'entre les enquadernacions barroques, destaca especialment un exem-

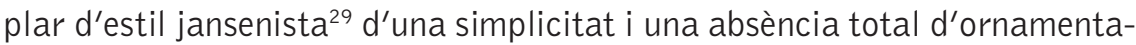
ció que contrasta fortament amb la resta d'enquadernacions d'aquest estil. Es va desenvolupar a França entre els segles XviI i xviII i deu el nom als seguidors de Cornelius Jansen (1585-1683).

A principis del segle XVIII, el barroc comença un període de transició que culmina amb I'aparició de I'estil rococó, nascut a França durant el regnat de Lluís xiv. A Espanya, el rococó va coincidir aproximadament amb el regnat de Ferran vi. Les enquadernacions rococós es caracteritzen per
27 López Serrano, Matilde, Biblioteca de Palacio: encuadernaciones, Madrid, Afrodisio Aguado, 1950.

28 Les reials audiències, audiències reials 0 audiències, i també cancelleries eren els màxims òrgans de justícia als estats de la Monarquia d'Espanya entre el segle XVI i xvII. Les cancelleries castellanes es distingien de les simples reials audiències pel fet $d^{\prime}$ 'estar presidides per un canceller i tenir, a més, atribucions governatives.

29 El jansenisme va ser un moviment religiós iniciat pel teòleg i bisbe Cornelius Jansen (1585-1638), que va gaudir d'una certa popularitat a Europa durant els segles XVII i xVII. Va ser condemnat com a herètic per l'Església Catòlica. 
${ }^{30}$ Cuir de cabrit molt prim, brunyit i llustrós. tenir l'ornamentació daurada de les tapes a base de dissenys curvilinis molt elaborats, ondulants i sinuosos. Hi destaca la utilització de ferros amb forma de fulles d'acant, ocells, flors, fistons, rocalles, garlandes, etc.

Dins de l'estil rococó es van desenvolupar dos tipus d'enquadernacions, presents a la col·lecció: el de mosaic i el d'orla de puntes. Les enquadernacions de mosaic utilitzen la policromia a partir de l'ús de pells de diferents colors; les d'orla de puntes prenen els motius de les puntes de coixí i normalment estan realitzades en tafilet $^{30}$ vermell.

També hi ha un parell d'enquadernacions d'estil neoclàssic, un moviment caracteritzat per la cerca de I'harmonia, I'equilibri i la senzillesa en la composició que contrasta amb els excessos que havia tingut I'estil roco-

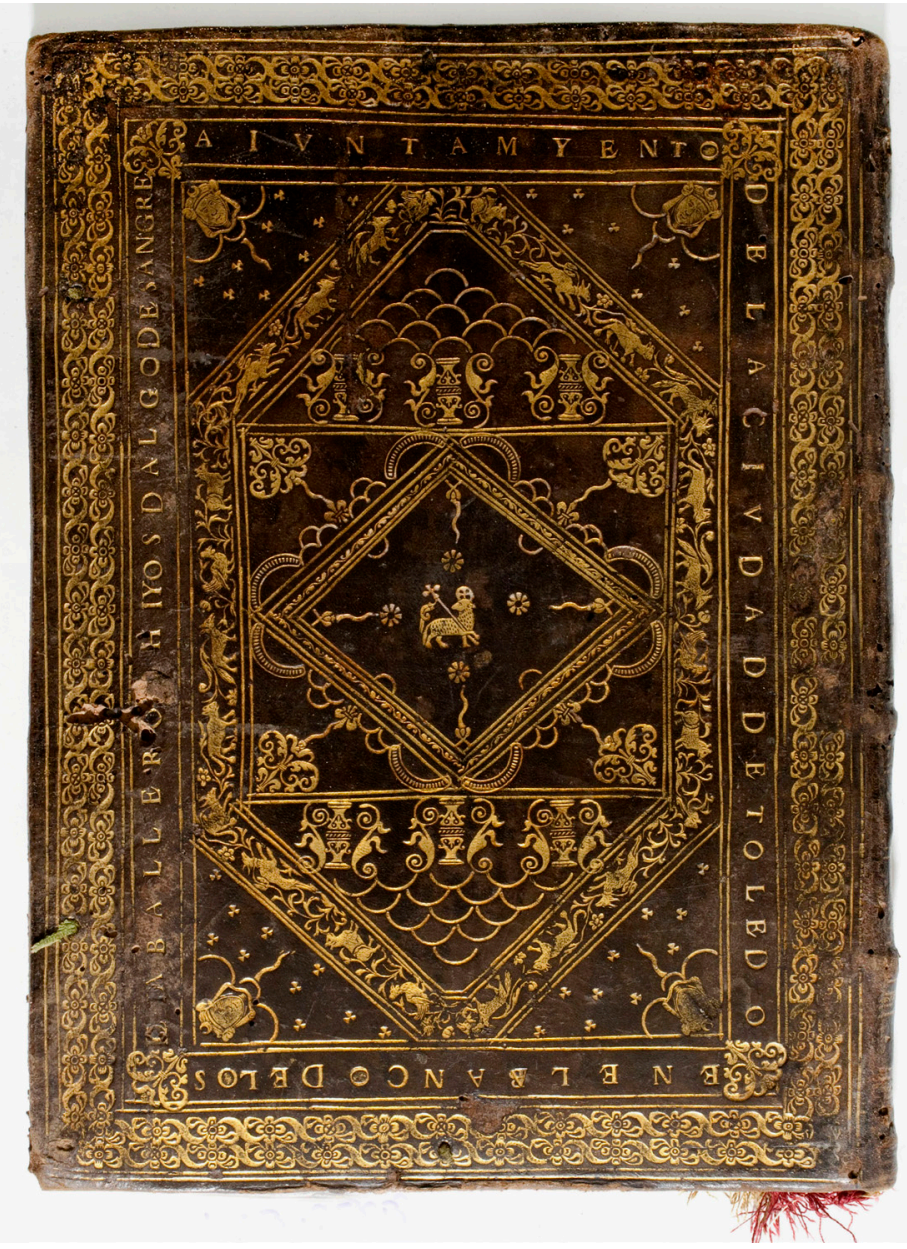

Fig. 3. Enquadernació de tipus populars 
có. Se substitueixen les formes ondulades per les rectilínies, es restringeix I'ús de ferros solts i es torna a l'aplicació de la roda. Els motius de rocalla i fulles d'acant són substituïts per motius clàssics grecoromans, concentrats principalment en el Ilom.

La col-lecció també compta amb dos exemples d'enquadernacions d'estil imperi, que va triomfar de forma efímera durant el període 1814-1831 i que, a Espanya, va tenir un cert ressò durant el regnat de Ferran viı. Les tapes es decoraven amb orles més amples que les de les enquadernacions neoclàssiques. La intersecció de les rodes formaven quadrats en les cantonades, que podien contenir algun motiu decoratiu al seu interior. Al Ilom apareixien nervis simulats.

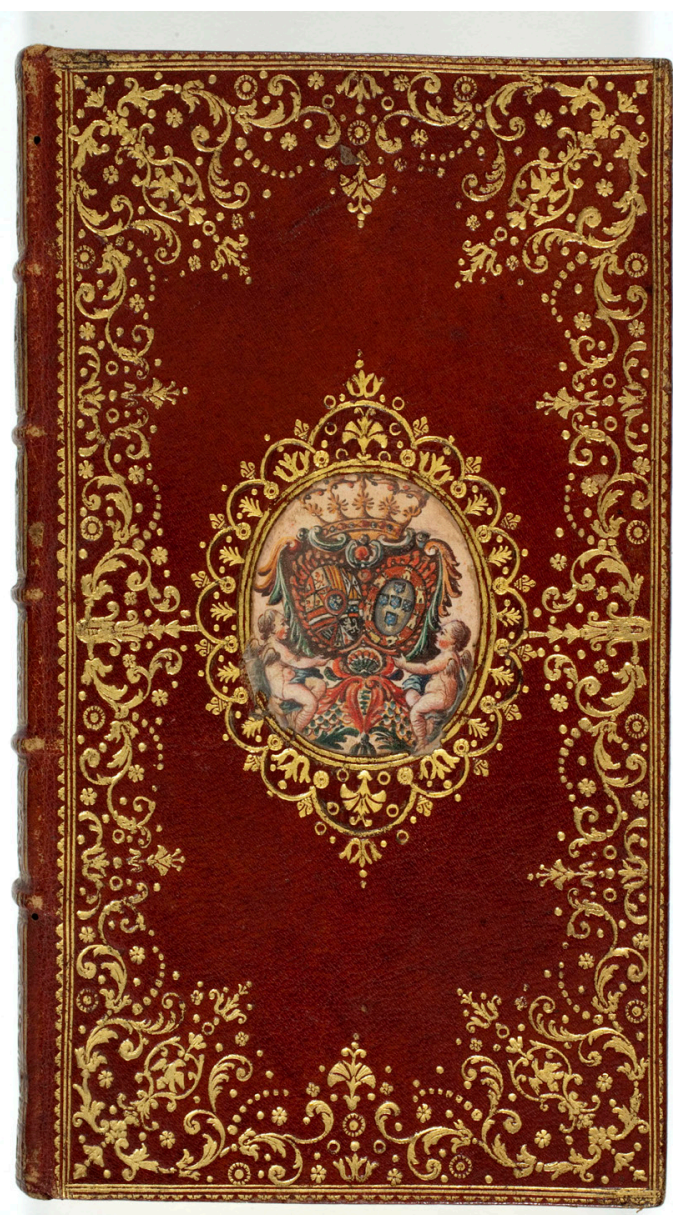

Fig. 4. Enquadernació d'orla de puntes 
${ }^{31}$ Les guies de forasters començaren a editar-se I'any 1772 amb el títol de Kalendario manual y guía de forasteros en Madrid. Es publicaven amb periodicitat anual i consistien en un directori de l'estructura organitzativa de l'Estat, un calendari, un santoral, dades astronòmiques i festivitats.

${ }^{32}$ L'enquadernació heràldica es caracteritza per presentar com a element decoratiu un escut $d^{\prime}$ armes o altres motius heràldics.

33 Breviarium cartusianum, Venetiis, Andree Thoresani de Asula, tertio nonas maii, 1491.

34 Expedient ANCl715-T-496: "Acta de la sessió de la Junta de Museus de Barcelona de 14.03.1914». Imatges 3-4/11.

${ }^{35}$ Breviarium cartusianum, Venetiis, Andree Thoresani de Asula, tertio nonas maii, 1491. (https://ccuc.csuc.cat/recor$d=b 4531341 \sim$ S34 ${ }^{*}$ cat)

36 Salvador Babra era el propietari de la Llibreria Antiga i Moderna, situada al carrer de la Canuda de Barcelona. Alexandre de Riquer així ho afirma en una carta adreçada a la Junta de Museus i que esta datada el 22 de juliol de 1914. Expedient ANC1-715-T-2124: "Sessió del 24 d'octubre de 1914 de la Junta de Museus de Barcelona». Imatge 20/64.
El Romanticisme es va originar a Alemanya i s'estengué per Europa durant el primer terç del segle XIx. Els seus eixos eren la reacció al neoclassicisme i un retorn al medievalisme. En el camp de l'enquadernació, la influència romàntica va generar un estil decoratiu caracteritzat per la decoració de les tapes a partir de diversos fils paral·lels que emmarquen un motiu central. A la col·lecció d'Alexandre de Riquer es conserven exemples de dos models molt típics d'enquadernacions romàntiques. D'una banda, tenim les denominades «a la catedral», que s'inspiren en els motius decoratius de les catedrals gòtiques i que van ser molt comuns a França a partir de I'any 1882 gràcies a I'enquadernador Joseph Touvenin. D'altra, trobem les enquadernacions de planxes que utilitzen una gran planxa central amb motius decoratius molt recarregats.

Per finalitzar aquest apartat, esmentarem dos grups d'enquadernacions presents a la col·lecció que, sense pertànyer a un estil concret, són molt significatives. D'una banda, tenim les guies de forasters, ${ }^{31}$ grup àmpliament representat atès que tots els exemplars espanyols del segle XIX que hi ha a la col·lecció ho són. D’altra trobem el conjunt format per les enquadernacions heràldiques, ${ }^{32}$ que reprodueixen en una o ambdues tapes un escut d'armes, un emblema heràldic o una marca de propietat. La col·lecció d'Alexandre de Riquer té exemplars que abasten des del segle xvi fins al segle XIX, sens perjudici que també puguin pertànyer a algun dels estils que hem explicat.

\section{L'exemplar del Breviarium cartusianum ${ }^{33}$ comprat I'any 1914}

L'any 1914 la Junta de Museus va comprar a Alexandre de Riquer un exemplar incunable editat a Venècia I'any 1491. La compra del susdit exemplar va ser aprovada per quatre-centes pessetes en la sessió ordinària de la Junta Museus que va tenir lloc el dia 14 de març de 1914. Segons es desprèn de la lectura de les actes de la Junta, la compra va ser motivada per la seva notable enquadernació ${ }^{44}$ i, per aquesta raó, I'exemplar es va sumar a la col·lecció d'enquadernacions del 1909 i va passar a formar part del fons del Museu d'Art Decoratiu i Arqueològic. Va ingressar en els fons de la biblioteca l'any 1948, juntament amb la resta de la col·lecció de relligadures.

L'exemplar que la Junta va adquirir era un breviari de l'orde dels cartoixans ${ }^{35}$ que I'artista Alexandre de Riquer havia adquirit a I'antiquari Salvador Babra de Barcelona. ${ }^{36}$ Els breviaris són llibres litúrgics d'escasses proporcions, el que facilitava el transport i permetia l'oració privada de 
I'Ofici Diví. El culte privat era una pràctica consumada des de finals del segle xIv i principis del xv i es va consolidar amb la celebració del concili ecumènic de Basilea (1431-1445).

Segons el bibliotecari i bibliògraf Hanns Bohatta, ${ }^{37}$ en època incunable es van fer tres edicions del breviari cartoixà: dos van ser realitzades per I'impressor Andrea Torressano, en els anys 1491 i 1500 respectivament, i la tercera, és una edició sine notis. ${ }^{38}$ Gràcies a la consulta de la base de dades Gesamtkatalog der Wiegendrucke ${ }^{39}$ també comprovem que, fins el 1500, es van fer tres edicions del breviari però, a diferència de Bohatta, es considera que la tercera no és una edició sine notis sinó que va ser impresa a Venècia el 1500 per Theodorus de Ragazonibus. Per la consulta d'aquesta base de dades, sabem que només es conserven exemplars de I'edició d'Andrea Torresano de I'any 1491. Malgrat això, per la descripció que ofereix Bohatta, podem afirmar que les tres edicions del breviari tenien una extensió semblant i que estaven impreses a dues columnes de trenta-cinc línies.
37 Bohatta, Hanns, Katalog der Inkunabeln der Fürstlichen Liechtenstein'schen Fideikommis-Bibliothek und der Hauslabsammlung, Hildesheim, G. Olms, [1961].

38 Una edició sine notis és una edició sense cap indicació de I'impressor, I'any o el lloc d'edició.

${ }^{39}$ "Breviarium», Gesamtkatalog der Wiegendrucke [en línia] consultat el 24/3/2011, disponible a https://www.gesamtkatalogderwiegendrucke. de/GWEN.xhtml

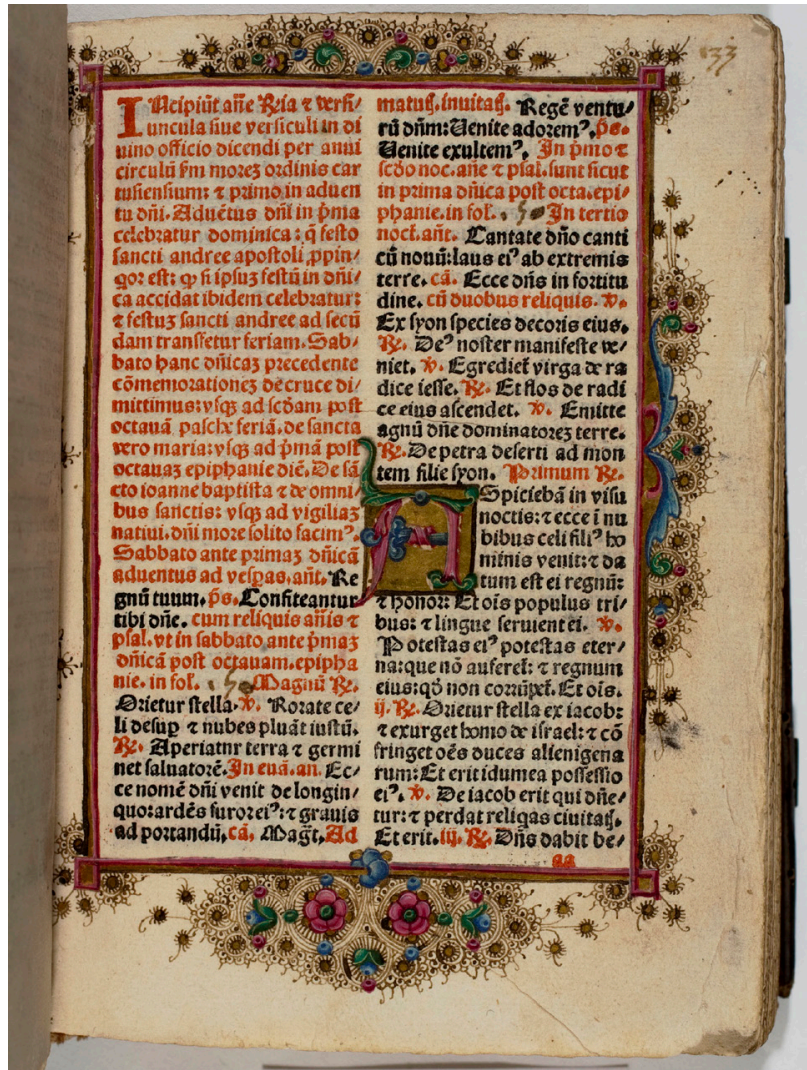

Fig. 5. Breviarium cartusianum 
${ }^{40}$ Altre part de la biblioteca privada va ser adquirida per la Biblioteca de Catalunya I'any 1924 per un preu de quatre mil pessetes. Segons consta al llibre de registre, el 14 d'abril de 1924 es va començar a registrar un conjunt d'obres impreses adquirides per compra als hereus d'Alexandre de Riquer. D’un total de 442 obres, la major part són monografies dels segles XVIII i XIX, però també hi ha llibres -menys- dels segles XvI $i$ xvII, i també del segle xx (publicacions en sèrie). Hi predomina la literatura i hi ha títols en Ilatí, francès, català, italià, castellà i anglès. (Consulta realitzada a la Biblioteca de Catalunya el mes de gener del 2014; dades extretes del vol. 16 del llibre de registre, corresponent als anys 19231926, p. 136-152).

41 Expedient ANCI715-T-625 «Acta de la sessió de la Junta de Museus de Barcelona de 21.01.1921». Imatge 9/9.

42 Expedient ANCl715-T-629 «Acta de la sessió de la Junta de Museus de Barcelona de 08.04.1921». Imatge 9/12.

43 Expedient ANCl715-T-630 «Acta de la sessió de la Junta de Museus de Barcelona de 22.04.1921». Imatges 1-3/7.

${ }^{44}$ Expedient ANC1-715-T632 «Acta de la sessió de la Junta de Museus de Barcelona de 27.05.1921». Imatges 4-5/6.

45 Expedient ANCl715-T-634 «Acta de la sessió de la Junta de Museus de Barcelona de 01.07.1921». Imatge 6/8.

\section{La biblioteca privada d'Alexandre de Riquer adquirida I'any 1921}

L'any 1921, un cop traspassat Alexandre de Riquer, la Junta de Museus va comprar als seus hereus les col·leccions de dibuixos, exlibris, gravats, cartells i una part de la seva biblioteca privada. ${ }^{40}$

A la sessió del 21 de gener de 1921, Joaquim Folch i Torres informava la Junta de Museus d'un viatge que havia realitzat a Mallorca per conèixer de primera mà les col·leccions que havien pertangut al difunt Alexandre de Riquer.

La Junta acordà autoritzar-lo per a iniciar la gestió de compra d'allò que considerés oportú. ${ }^{41}$ Així, el dia 8 d'abril d'aquest mateix any es posava en coneixement de la Junta que els hereus de l'artista havien ofert a la venda la seva biblioteca, una col·lecció de pintures, una sèrie de gravats i també una de dibuixos, acordant-se informar de la susdita proposta, en la part que els hi corresponia, a les comissions de biblioteca i d'art contemporani respectivament. ${ }^{42}$

El 22 d'abril d'aquell any, es presentà el dictamen favorable de la comissió de la biblioteca respecte l'adquisició del lot de llibres, exlibris i gravats per disset mil pessetes. A la mateixa sessió també es presentà el dictamen favorable de la comissió d'art contemporani relatiu a l'adquisició d'un quadre d'Eugenio Lucas, un grup de quaranta-quatre dibuixos de Goya i cent vuitanta dibuixos d'altres autors per un preu de dinou mil pessetes. ${ }^{43}$ Els dictàmens favorables quedaven, però, supeditats a la liquidació de les consignacions de les quals disposava la Junta de Museus.

En la sessió ordinària del 27 de maig de 1921, s'informa de la conformitat dels hereus d'Alexandre de Riquer amb la venda de la seva Ilibreria, els exlibris i els gravats i també de la col·lecció de dibuixos pels preus proposats. ${ }^{44}$ El primer de juliol del mateix any s'adoptà la resolució en ferm de la compra per un preu conjunt de trenta-sis mil pessetes amb consignació als fons municipals del present exercici. ${ }^{45}$

La col·lecció de dibuixos va ingressar en el Museu d'Art i Arqueologia del Parc de la Ciutadella. En canvi, les col-leccions d'exlibris, de gravats, de cartells i la seva biblioteca foren ingressades en la Biblioteca dels Museus d'Art. Actualment, a la Biblioteca Joaquim Folch i Torres únicament es conserva la biblioteca privada de l'artista atès que les col·leccions d'exlibris, gravats i cartells es disgregaren del seu fons per passar a formar part del fons Gabinet de Dibuixos i Gravats del Museu Nacional d'Art de Catalunya.

Com ja hem explicat, el treball se centra en els fons bibliogràfics conservats a la Biblioteca Joaquim Folch i Torres. Per aquesta raó, només ens detindrem a parlar de la biblioteca d'art d'Alexandre de Riquer. Segons 
I'inventari de I'any 1921, la Junta de Museus va adquirir un total de 421 llibres i revistes (amb 689 unitats físiques). ${ }^{46}$

Abans d'aprovar la compra, la comissió de la biblioteca va fer un dictamen a que fou signat pel bibliotecari Esteve Cladellas. ${ }^{47} \mathrm{~A}$ la introducció es destaca el paper de guiatge artístic que Alexandre de Riquer va exercir «prodigant sense taxa els seus ensenyaments i sobretot posant a disposició dels joves la seva biblioteca d'art, sens dubte la més important de la ciutat». També ressalta «el segell comú d'estrangeria» de les seves obres fins «al punt de que el visitant no advertit, mai podria sospitar, en presència d'eixa biblioteca, que hagi nodrit I'esperit d'un artista tant essencialment català».

Creiem que Alexandre de Riquer era un artista molt ben informat, tant pels viatges realitzats a Londres com per la gran Iliçó d'art que es podia extreure de la seva biblioteca personal. La importància d'aquesta com a font d'inspiració i com una de les vies de penetració de la influència de l'art prerafaelita en el Modernisme català és un aspecte que ha estat assenyalat per diversos experts.

Eliseu Trenc i Ballester tracta el tema en dos estudis: el primer de I'any el 1982 i el segon, en col·laboració amb Alan Yates, de I'any 1988. ${ }^{48}$ D'altra banda, Rafael Cornudella, en un article sobre els cartells de Riquer, ${ }^{49}$ descobreix alguns manlleus iconogràfics d'artistes britànics, artistes als quals coneixia perfectament gràcies als llibres i revistes de la seva biblioteca.

Cristina de la Cuesta Marina, ${ }^{50}$ en la contribució al Congrés Nacional d'Història de l'Art celebrat a Palma de Mallorca, afirma: «el nombre más clara y decididamente ligado al arte prerrafaelista es el de Alexandre de Riquer, artista que supone uno de los enlaces más directos e importantes entre la Pre-Raphaelite Brotherhood y el arte modernista catalán. [...] En su papel de enlace entre el Prerrafaelitismo y el arte modernista catalán resulta crucial su biblioteca [...]».

Finalment, Pilar Vélez ${ }^{51}$ destaca que I'artista «tenia una biblioteca notable [....]. Això explica que Riquer sempre estigués al dia de I'actualitat artística internacional del seu temps i, sens dubte, en la seva obra gràfica i decorativa en general, s'hi troben algunes referències a d'altres artistes contemporanis, un fet gens estrany entre els artistes ben informats, d'ahir i d'avui».

\section{Composició de la biblioteca}

Esteve Cladellas assenyala que els documents que conformaven la biblioteca privada d'Alexandre de Riquer eren el reflex dels «trets característics de la seva personalitat i el desenrotllament gradual de les seves iniciatives artístiques».52 Segons això, va classificar la col·lecció bibliogràfica en cinc
46 Arxiu del Museu Nacional $d^{\prime}$ Art de Catalunya, Fons Biblioteca dels Museus d'Art, Biblioteca d'art Alexandre de Riquer, R. 861.

47 Expedient ANCl715-T-2318: «Sessió del 22 d'abril de 1921 de la Junta de Museus de Barcelona». Imatges 9-24/72.

48 Trenc Ballester, Eliseu, "Alexandre de Riquer, ambassadeur de I'art anglais et nord-americain en Catalogne», Mélanges de La Casa de Velázquez, vol. XVIII. núm. 1, 1982, p. 311-359.

Trenc Ballester, Eliseu; YATES, Alan, Alexandre de Riquer: 1856-1920: the British connection in Catalan modernisme. Sheffield, The Anglo-Catalan Society, 1988.

${ }^{49}$ Cornudella i Carré, Rafael, "Sobre els cartells d'Alexandre de Riquer i les seves fonts", Locus Amoenus, núm. 1, 1995, p. 227-247.

${ }^{50}$ Cuesta Marina, Cristina, «Vías de penetración de la influencia prerrafaelita en la pintura catalana de finales del siglo XIX». Modelos, intercambios y recepción artística de las rutas marítimas a la navegación en red: Palma de Mallorca, 20-23 de octubre de 2004, Palma, Universitat de les Illes Balears, Edicions UIB, Cas Jai, 2008, p. 674.

51 VéLez, Pilar, «Alexandre de Riquer: "I'esperit decoratiu" en les arts del llibre», Alexandre de Riquer: obra gráfica, [Terrassa], Caixa Terrassa, 2006, p. 135-150.

52 Segons consta en l'informe que he citat amb anterioritat: Expedient ANCl715-T-2318: "Sessió del 22 d'abril de 1921 de la Junta de Museus de Barcelona». Imatges 9-24/72. 
53 La guarda és el full que I'enquadernador posa entre el llibre i cadascun dels cartons de la coberta, la meitat del qual s'enganxa a la cara interior del cartó i que, generalment, són d'un material diferent a I'utilitzat en el cos del Ilibre.

54 Riquer, Alexandre, Robert $A$. Bell, Vilanova i la Geltrú, Imp. Oliva, 1910, p. 17.

55 Riquer és l'autor d'un article en el primer número de la revista Joventut, tot fent-se ressó de la forma en que va aparèixer el primer article sobre Beardsley a la Gran Bretanya, aparegut en el número inaugural de l'any 1893 de la revista The Studio. La coincidència és deliberada atès que Riquer coneixia l'article escrit per Joseph Pennell i era el director artístic de la revista que pretenia ser l'equivalent català de la revista anglesa. Trenc Ballester, Eliseu; YATES, Alan, Alexandre de Riquer..., p. 114.

56 Aquest exemplar es troba actualment deslocalitzat.

57 Mostra de la seva admiració és I'estudi que li dedicà I'any 1910. Riquer, Alexandre, Robert A. Bell...

58 El parer de Riquer era que es tractava d'un llibre «bien presentado, bien impreso, pero escaso de márgenes, especialmente en su parte superior. Además de esto, la mayoría de las acuarelas tienen por marco una gruesa franja que las perjudica y la tricomonía es deficiente». Tot i això, pensava que el llibre era «[...] muy recomendable, siendo de desear un mayor respeto de los originales por parte de los editores $[. .]. » \mathrm{R}_{\mathrm{I}}-$ QUER, Alexandre, Robert $A$. Bell..., p. 18-19. apartats temàtics que nosaltres aprofitarem per oferir una panoràmica sobre el contingut de la biblioteca: Ilibres il.lustrats, llibres sobre exlibris, llibres sobre cartellisme, monografies de pintors i d'altres branques de l'art i, per últim, les revistes. A aquests cinc grups, se'ls hi pot afegir un petit nucli d'obres que no s'encabeixen en cap dels grups anteriors i que està format per un incunable, tres reculls facticis i tres àlbums de guardes ${ }^{53}$ decorades.

\section{Llibres il·lustrats}

La biblioteca d'Alexandre de Riquer compta amb un bon nombre $d^{\prime}$ obres il.lustrades, entre les que distingim tres grups.

El primer grup està format per les obres de quatre il.lustradors anglesos: Aubrey Beardsley, Robert Anning Bell, Arthur Rackham i Alice B. Woodward. Alexandre de Riquer admirava els il|lustradors anglesos i opinava que «son siempre correctos, cuidadosos en su producción». ${ }^{54}$

En especial, sentia admiració per Aubrey Beardsley ${ }^{55}$ i la seva biblioteca comptava amb diversos volums de I'artista anglès: Bon-mots of Charles Lamb and Douglas Jerrold, Bon-mots of Samuel Foote and Theodore Hook i Bon-mots of Sydney Smith and R. Brinsley Sheridan, de I'editorial J. M. Dent \& Co. D'aquest editor també tenia la Morte d'Arthur, un clàssic de la il.lustració Art Nouveau. Altres dues obres cabdals il|lustrades per Beardsley que Riquer posseïa són I'edició en anglès de I'obra Salomé d'Oscar Wilde de I'any 1894, i The Rape of the Lock $^{56} \mathrm{~d}^{\prime}$ Alexander Pope editat a principis del 1896.

Robert Anning Bell ${ }^{57}$ també era admirat per Alexandre de Riquer. L'artista tenia en la seva biblioteca A midsummer's night dream de I'any 1895, el primer treball important de l'il/lustrador anglès. Altres obres de Robert Anning Bell presents a la biblioteca de Riquer són Poems (1897), English lyrics from Spencer to Milton (1898) -tots dos de I'editorial George Bell and sons-, Grimm's household tales (1901), The tempest (1901), considerada pels experts com el millor treball de Bell, i Palgrave's golden Treasury (1906), una antologia de poetes anglesos. ${ }^{58}$

Alexandre de Riquer posseïa diversos exemplars il.lustrats per Arthur Rackham: Rip van Winckle (1905), Kingdoms curious (1905) i The Ingoldsby and legends or Mirth and marvels (1907), de I'editorial Heinemmann Publishers. Altres obres il|lustrades per aquest il.lustrador que formaven part de la seva biblioteca privada són The land of enchantment (1907), The fairy tales of the Brothers Grimm (1909), A midsummer-night's dream (1908), Undine (1909) i The Rhinegold and the Valkyrie (1910). 


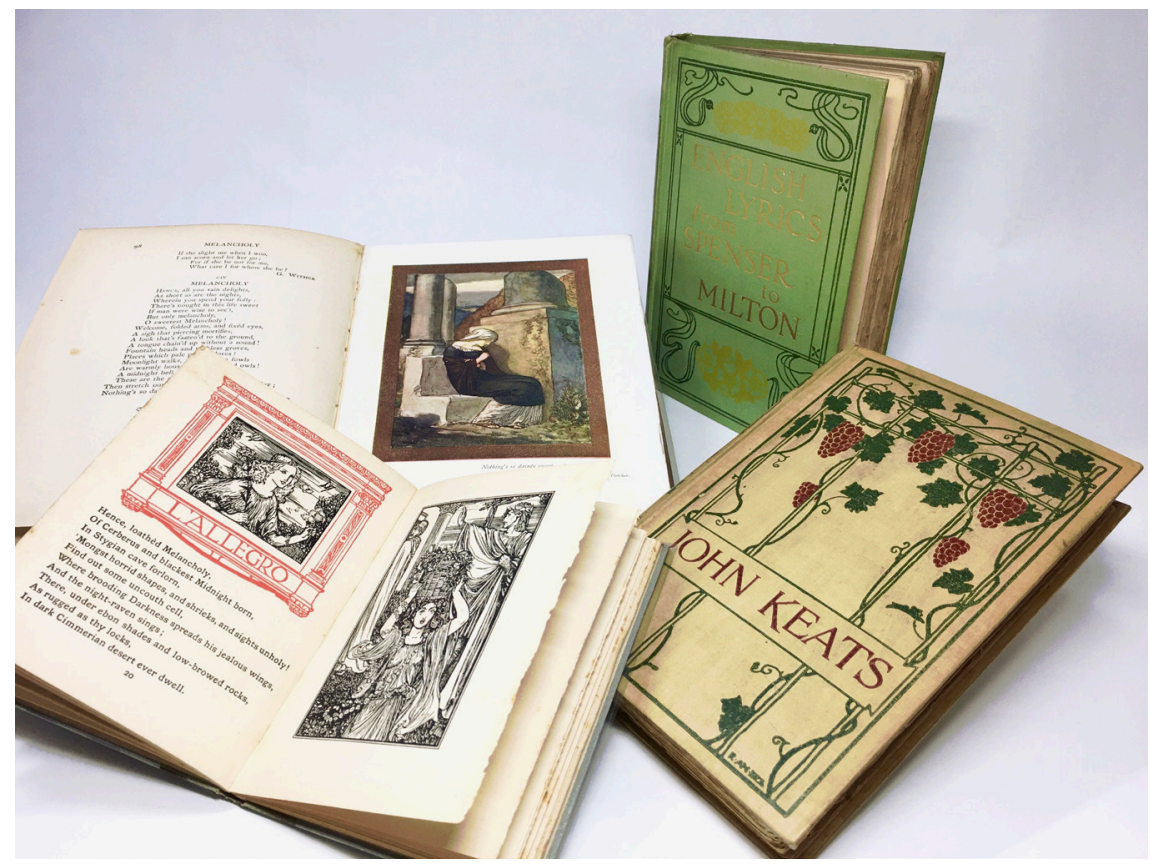

Fig. 6. Llibres il.lustrats per Robert Anning Bell

De I'artista Alice B. Woodward, Riquer tenia els següents llibres: To Tell the King the Sky is Falling (ca. 1896) i Red Apple and Silver Bells (1899), publicats per I'editorial Blackie and Son, i My friend poppity (1900), de I'editorial David Nutt de Londres.

$\mathrm{Hi}$ ha un segon grup format per llibres il.lustrats d'altres artistes, entre els quals predominen els dibuixants anglesos (Percy J. Billinghurst, Katharine Cameron, Jessie Marion King, Byam Shaw, etc.) però també hi ha obres d'artistes estatunidencs (Edwin Austin Abbey o William Henry Bradley) això sí, amb influències prerafaelites. També s'hi troben artistes francesos (André Cahard, Champollion, Adrien Moreau, Luc-Olivier Merson, Odilon Redon etc.), alemanys (Adolf von Menzel, Emil Preetorius), austríacs (Franz von Bayros) i espanyols (Daniel Vierge).

Per últim, podem diferenciar encara un tercer grup conformat per obres no literàries il-lustrades que esdevenen interessants exemples del grafisme de I'època. Hi ha un calendari de 1900 il-lustrat de per Koloman Moser, una carta de vins il·lustrada per Paul Bürck o una publicació que recull les cobertes de la revista Inland printer, segurament la primera en utilitzar una coberta diferent per a cada número i que jugà un paper molt important en la popularització de I'estil Art Nouveau als Estats Units. 


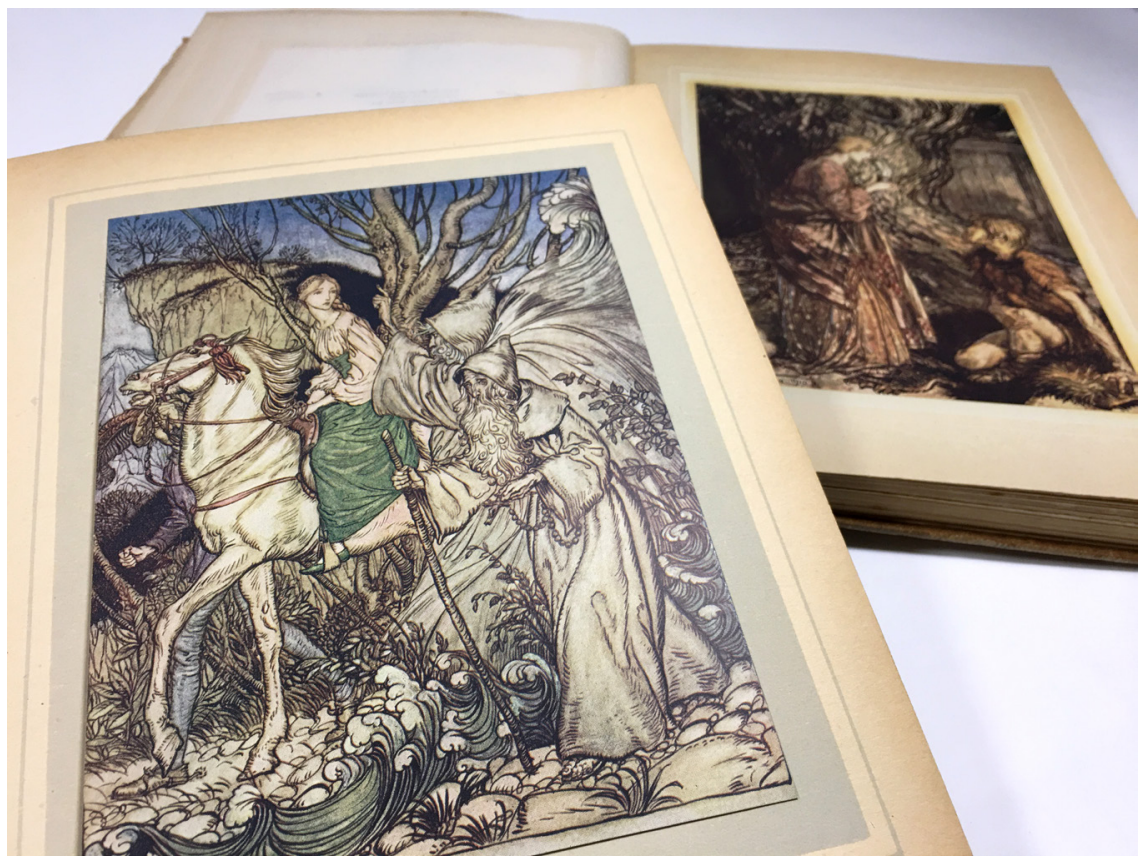

Fig. 7. Llibres il.lustrats per Arthur Rackham

\section{Llibres sobre exlibrisme}

Tal i com es pot esperar d'un col-leccionista, assagista i dissenyador d'exlibris, la biblioteca privada d'Alexandre Riquer compta amb un bon nombre d'obres sobre exlibrisme que s'agrupen en tres grans blocs temàtics.

El primer bloc està format per monografies d'exlibristes, majoritàriament d'origen estatunidenc, però també trobem monografies sobre Joaquim Renart i Josep Triadó, artífexs del renaixement de I'exlibris a Catalunya. Molts dels exemplars que en formaven part tenen un tiratge reduït $i$ contenen I'autògraf de l'artista.

El segon grup el constitueixen les monografies generals sobre l'exlibrisme. Trobem I'obra de Ramon Miquel Planas sobre el renaixement $d$ 'aquest art a Espanya publicat el 1905 i un treball d'Alexandre de Riquer datat el 1902. Altrament, hi ha un grup d'obres que agrupen els exlibris temàticament com, per exemple, una obra sobre les marques de propietat amb imatges de Beethoven (Beethoven-Exlibris, 1906) o altra que tracta dels exlibris realitzats per dones (Women designers of book-plates, 1902).

Finalment, tenim el grup que inclou els catàlegs de col·leccions privades d'exlibris. A França, el ressorgiment de l'exlibris tingué més un caràcter de redescoberta i de publicació de les marques antigues que de creació de 
marques modernes i, per aquesta raó, s'editaren molts catàlegs de col·leccions privades. Els exemplars de la biblioteca d'Alexandre de Riquer estaven editats per I'editorial Saffroy Frères ubicada al municipi de Le PréSaint-Gervais i pels editors Em. Paul et fils et Guillemin de París.

\section{Llibres sobre cartellisme}

Sorprèn el nombre reduït de Ilibres sobre cartells que hi ha a la biblioteca d'Alexandre de Riquer. N'hi ha dues explicacions possibles i, alhora, complementàries: probablement, la informació sobre cartellisme I'anà adquirint a base d'exemplars que "va anar adherint a les pàgines d'un luxós àlbum que duu al Ilom la data de 1898 ${ }^{59}$ i també convé recordar que la seva producció de cartells es circumscriu als anys 1896-1902 i que sembla que gradualment es va desinteressar pel tema.

\section{Monografies de pintors i d'altres branques de l'art}

Aquest és I'apartat més eclèctic de la biblioteca de Riquer. Trobem, $d^{\prime}$ 'una banda, monografies de pintors i, d'altra, llibres sobre diverses branques de l'art.

En el primer bloc, hi ha estudis sobre els pintors prerafaelites (Edward Burne-Jones, Frederic Leighton, Dante G. Rossetti, John Everett Millais) tan admirats per Alexandre de Riquer. També hi ha monografies sobre representants del moviment Arts \& Crafts (William Morris), I'esteticisme (James McNeill Whistler), el simbolisme (Carlos Schwabe i Pierre Puvis de Chavannes), el realisme (Adolph Menzel), el paisatgisme (Thomas Gainsborough), primitius flamencs (Van Eyck i Hans Menling), artistes del Renaixement italià (Leonardo da Vinci, Fra Angelico, Sandro Botticelli, Filippino Lippi, Rafael, Miquel Àngel, Andrea Mantegna, Donatello, Luca Signorelli, Perugino, Piero della Francesca i Carlo Crivelli), pintors alemanys (Hans Holbein el jove i Albert Durer), artistes francesos del segle xvin (Jean-Antoine Watteau, Jean Honoré de Fragonard i Elisabeth Louise Vigée le Brun), artistes de I'Escola de Barbizon (Theodore Rousseau i Jean-François Millet) i artistes del Romanticisme (Alexandre Gabriel-Decamps). Altrament, inclou monografies de pintors espanyols i catalans (Francisco de Goya i Marià Fortuny). També trobem I'estudi sobre el pintor japonès Hokusai que va realitzar el col-leccionista i marxant $d^{\prime}$ art Friedrich Perzinsky, com també un conjunt de preciosos llibres japonesos il·lustrats que fan ben evident I'interès de Riquer tenia pel japonisme. ${ }^{60}$
59 LABORDA, Adela, «La collecció d'ex-libris del Museu Nacional d'Art de Catalunya. Els principals episodis formatius $d^{\prime}$ un fons patrimonial singular», XXXV Congrés Internacional d'EX-libristes, Tarragona, Associació Catalana d'Exlibristes, 2014, p. 220-264.

60 Ruiz Ruiz, Yolanda, «El japonisme i la seva presència a la biblioteca del museu», [en línea] https://blog.museunacional.cat/el-japonisme-a-la-biblioteca-del-museu/ (consultat 12/1/2021) 
${ }^{61}$ Viollet-le-Duc, Eugène, Dessins inédits de VioIlet-le-Duc, París, Armand Guérinet, 1900.

Viollet-Le-Duc, Eugène, Dictionnaire raisonné du mobilier français de l'époque carlovingienne à la Renaissance, $\mathrm{Pa}$ rís, Ve. A. Morel et Cie, 1871.

62 La col-lecció inclou els núms. 1-231, inclosos així com els números special number.
En canvi, Riquer no es mostrava gens receptiu amb els artistes naturalistes o impressionistes, dels quals no hi ha cap representació.

Moltes de les monografies sobre pintors pertanyen a col·leccions editorials com Classiques de l'art, de la Librairie Hachette \& cie.; Grands artistes, de I'editorial Henri Laurens; Great masters in painting and sculpture, de George Bell and Sons; Maîtres de l'art i Peintres illustrés, de la Librairie d'Art Ancien et Moderne; i Künstler Monographien, de I'editorial Velhagen und Klasing.

El segon bloc, molt heterogeni, està format per obres sobre diverses disciplines i tècniques artístiques (arquitectura, arts decoratives, ceràmica, dibuix i caricatura, escultura, fotografia, gravat, heràldica, història, il·lustració de llibres, joieria, pintura, etc.). Podem dir que les obres d'arquitectura que hi havia a la biblioteca mostren l'interès d'Alexandre de Riquer per I'arquitectura civil i I'arquitectura gòtica. Hi ha un parell d'obres de I'arquitecte Viollet-le-Duc ${ }^{61}$ com també I'edició en francès de Les sept lampes de l'architecture, de John Ruskin, editada a París el 1900 per la Société d'Édition Artistique.

D'altra banda podem trobar obres sobre I'art gòtic, l'art japonès o l'art bizantí. Els llibres d'escultura són predominantment d'escultors clàssics i d'escultura medieval. Entre les obres de pintura, trobem una certa preferència pels primitius italians amb alguns estudis sobre els prerafaelites.

Altrament, hi ha un grup de llibres sobre arts decoratives i ceràmica, lògic si tenim en compte que Alexandre de Riquer fou artista decorador; com també és raonable trobar estudis sobre dibuix, gravat i il.lustració atès que les arts gràfiques foren un dels camps on I'artista es desenvolupà professionalment. També trobem obres que fan palès I'interès de Riquer per la bibliofília i les enquadernacions artístiques. Per finalitzar, crida l'atenció un grup d'obres sobre la fotografia, sobretot perquè és un terreny amb el que no va mantenir cap vincle professional.

\section{Revistes}

$\mathrm{Hi}$ ha publicacions de procedència anglesa, francesa i alemanya entre les quals trobem les revistes sobre art més rellevants de l'època. Alexandre de Riquer estava subscrit a la important revista artística The Studio ${ }^{62}$ que va exercir una gran influència en el desenvolupament del moviment Arts and Crafts.

La seva col·lecció de revistes demostra certa preferència envers les revistes $d^{\prime}$ arts decoratives i les revistes especialitzades en gravats i carteIlisme. Trobem importants revistes modernistes (Luz: periódico quincenal 
de arte moderno, Jugend i Pan), sobre bibliofilia ( The Bibliophile: a magazine and review for the collector, student and general leader i The Book-lover's magazine), cartellisme (Les maîtres de l'affiche), exlibris (Exlibris, Buchkunst und Angewandte Graphik, Exlibris: zeitschrift für Bücherzeichen Bibliothekenkunde und Gelehrtengeschichte, Revista ibérica de exlibris i Rivista italiana di Exlibris), etc.

També hi ha números solts de diverses revistes d'ambit anglosaxó i americà: ${ }^{63}$ The graphic, The green Sheaf, The Quest, The Dome, The Elf $\mathrm{i}$ Bradley, his book. Entre les revistes franceses es troben els següents títols: Art et Décoration, L'Art et I'Idée, L'Image, La Plume, etc.

\section{Reculls facticis i altres documents remarcables}

Existeix un petit nucli d'obres que no podem encabir en cap dels grups anteriors, conformat per alguns reculls facticis, una col·lecció de guardes i I'incunable Liber Chronicarum.

A l'inventari de la seva biblioteca privada hi consten tres reculls facticis de documents. El primer està format per prospectes i cobertes il|lustrades de llibres i revistes de finals del segle XIX. El segon el conformen un conjunt de retalls d'imatges de relligadures on hi ha, entre d'altres, 40 retalls d'illustracions de I'enquadernador Charles Meunier extrets de la revista Reliure d'art i tres calcs de relligadures antigues. Els dos primers reflecteixen I'interès de Riquer per les arts gràfiques i per les enquadernacions artístiques. En canvi, el tercer, és un recull de manuscrits constituït per alguns documents relacionats amb la història política i militar de Catalunya durant la segona meitat del segle Xvir.

A més a més, la Biblioteca Joaquim Folch i Torres també conserva una col·lecció de fulls de guardes. El recull aplega peces catalanes i espanyoles dels segles XVII i XIX, papers austríacs i francesos del XVIII, guardes alemanyes del XVII i XIX i guardes nord-americanes del segle XIX. Aquesta col-lecció, segons afirmació de Riquer, fou iniciada per Federico de Madrazo. ${ }^{64}$

Per últim, hi ha un exemplar de I'edició Ilatina de I'incunable Liber Chronicarum ${ }^{65}$ enquadernat en mitja pell i seda brocada vermella. LA Crònica de Núremberg va ser publicada originalment en llatí el 12 de juny de 1493. Des del principi, però, es va planejar fer una versió en alemany, que fou publicada el 23 de desembre de 1493. Els estudiosos estimen que es van imprimir aproximadament 1400-1500 còpies de I'edició Ilatina i entre 700-1000 de l'edició en alemany. S'estima que encara es conserven aproximadament unes 400 còpies Ilatines i unes 300 d'alemanyes.
63 Desconeixem com va aconseguir aquests exemplars.

${ }^{64}$ Expedient ANC1-715-T2124: "Sessió del 24 d'octubre de 1914 de la Junta de/ Museus de /Barcelona». Imatge 20/64.

${ }^{65}$ Atles històric que recorre les diferents etapes de la història de la humanitat segons la cosmovisió del segle $\mathrm{xv}$. 
És una obra profusament il·lustrada, el que la fa especialment preuada atès que en aquell temps fer llibres amb moltes imatges comportava un alt grau de dificultat. Els dos artistes responsables de la supervisió del disseny i la il-lustració de la Crònica foren Michael Wohlgemut (1434-1519) i Wilhelm Pleydenwurff (ca. 1450-1494). El jove Albrecht Dürer (1471-1528) era aprenent del taller quan van ser creats molts dels dissenys de les il.lustracions. Per aquest motiu, historiadors de l'art han explorat en detall les possibles connexions entre nombroses il-lustracions del Liber Chronicarum i les creacions posteriors de l'artista més famós del Renaixement alemany.

\section{Conclusions}

Aquest treball profunditza en el coneixement de les col-leccions bibliogràfiques que pertanyien a Alexandre de Riquer i que es conserven a la Biblioteca Joaquim Folch i Torres del Museu Nacional d'Art de Catalunya. Aquestes col-leccions mostren dues cares de I'artista català: d'una banda, la de bibliòfil amant dels llibres antics i rars que, gràcies a la seva bibliofília, va reunir un conjunt d'enquadernacions artístiques i un parell d'incunables; de I'altra, la del artista que, en I'exercici de la professió, va aplegar una important biblioteca d'art, la més important de Barcelona segons afirma el bibliotecari Esteve Cladellas. Aquesta biblioteca de consulta estava formada per obres predominantment estrangeres, sobretot britàniques que, com han assenyalat diversos experts, li serviren d'inspiració i significaren una de les vies de penetració de la influència de l'art prerafaelita en el Modernisme català. Encara avui en dia, moltes de les obres que en formaven part continuen sent exemplars únics en l'àmbit de les col·leccions públiques catalanes i espanyoles.

Yolanda Ruiz Ruiz

Museu Nacional d'Art de Catalunya yolanda.ruiz@museunacional.cat 
LES COL·LECCIONS BIBLIOGRÀFIQUES D'ALEXANDRE DE RIQUER A LA BIBLIOTECA JOAQUIM FOLCH I TORRES DEL MUSEU NACIONAL D'ART DE CATALUNYA

Gràcies a la bibliofília de I'artista Alexandre de Riquer, la Biblioteca Joaquim Folch i Torres del Museu Nacional d'Art de Catalunya conserva un interessant fons bibliogràfic patrimonial. Es tracta de la seva col·lecció d'enquadernacions artístiques, d'un exemplar incunable del Breviarium cartusianum i de part de la seva biblioteca privada. Tots aquests fons van ser adquirits per la Junta de Museus en anys diferents.

Paraules clau: Alexandre de Riquer, enquadernacions artístiques, Biblioteca Joaquim Folch i Torres, Museu Nacional d'Art de Catalunya, incunables, Breviarium cartusianum, biblioteca privada.

\section{ALEXANDRE DE RIQUER'S BIBLIOGRAPHIC COLLECTIONS AT THE LIBRARY JOAQUIM FOLCH I TORRES OF THE MUSEU NACIONAL D'ART DE CATALUNYA}

Due to the artist Alexandre de Riquer's bibliophilia, the Library Joaquim Folch i Torres of the Museu Nacional d'Art de Catalunya preserves an interesting collection of bibliographic heritage. This is the artist's own collection of artistic bookbindings, an incunabulum copy of the Breviarium cartusianum, as well as a part of its own library. The Junta de Museus acquired all of these bibliographic collections in different years.

Keywords: Alexandre de Riquer, artistic bookbindings, Library Joaquim Folch i Torres, incunabula, Museu Nacional d'Art de Catalunya, Breviarium cartusianum, private library. 
Aquest article ha estat publicat originalment a Matèria. Revista internacional d'Art (ISSN en línia: 2385-3387)

Este artículo ha sido publicado originalmente en Matèria. Revista internacional d'Art (ISSN en línea: 2385-3387)

This article was originally published in Matèria. Revista internacional d'Art (Online IS S N : 2385-3387)

\section{MATÈRIA}

Revista internacional d'Art

Els autors conserven els drets d'autoria i atorguen a la revista el dret de primera publicació de l'obra.

Els textos es difondran amb la llicència de Reconeixement-NoComercialSenseObraDerivada de Creative Commons, la qual permet compartir I'obra amb tercers, sempre que en reconeguin I'autoria, la publicació inicial en aquesta revista i les condicions de la llicència: https://creativecommons. org/licenses/by-nc-nd/4.0/deed.ca

Los autores conservan los derechos de autoría y otorgan a la revista el derecho de primera publicación de la obra.

Los textos se difundirán con la licencia de Atribución-NoComercial-SinDerivadas de Creative Commons que permite compartir la obra con terceros, siempre que éstos reconozcan su autoría, su publicación inicial en esta revista y las condiciones de la licencia: https://creativecommons.org/licenses/ by-nc-nd/4.0/deed.es

The authors retain copyright and grant the journal the right of first publication.

The texts will be published under a Creative Commons Attribution-NonCommercial-NoDerivatives License that allows others to share the work, provided they include an acknowledgement of the work's authorship, its initial publication in this journal and the terms of the license: https://creativecommons.org/licenses/by-nc-nd/4.0/deed.en

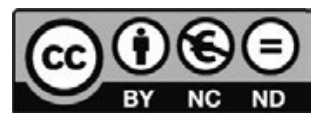

